\section{OPEN ACCESS}

Edited by:

Guido laccarino,

University of Naples Federico II, Italy

Reviewed by:

Marius Miglinas,

Vilnius University, Lithuania

Elise Peery Gomez-Sanchez,

University of Mississippi Medical

Center, United States

*Correspondence: Johannes Stegbauer

johannes.stegbauer@

med.uni-duesseldorf.de

tThese authors have contributed equally to this work

Specialty section:

This article was submitted to Hypertension,

a section of the journal

Frontiers in Cardiovascular Medicine

Received: 05 September 2021 Accepted: 03 January 2022

Published: 24 January 2022

Citation:

Kantauskaite M, Bolten K, Boschheidgen M, Schmidt C, Kolb T, Eckardt KU, Pasch A, Schimmöller L,

Rump LC, Voelkl J and Stegbauer J (2022) Serum Calcification Propensity and Calcification of the Abdominal Aorta in Patients With Primary Aldosteronism

Front. Cardiovasc. Med. 9:771096. doi: 10.3389/fcrm.2022.771096

\title{
Serum Calcification Propensity and Calcification of the Abdominal Aorta in Patients With Primary Aldosteronism
}

\begin{abstract}
Marta Kantauskaite ${ }^{1}$, Katharina Bolten ${ }^{1}$, Matthias Boschheidgen ${ }^{2}$, Claudia Schmidt ${ }^{1}$, Thilo Kolb ${ }^{1}$, Kai Uwe Eckardt ${ }^{3}$, Andreas Pasch ${ }^{4,5}$, Lars Schimmöller ${ }^{2}$, Lars C. Rump ${ }^{1}$, Jakob Voelk $\left.\right|^{3,4,6 t}$ and Johannes Stegbauer ${ }^{1 * t}$
\end{abstract}

\begin{abstract}
${ }^{1}$ Department of Nephrology, Medical Faculty, University Hospital Düsseldorf, Heinrich-Heine-University Düsseldorf, Düsseldorf, Germany, ${ }^{2}$ Department of Diagnostic and Interventional Radiology, Medical Faculty, University Hospital Düsseldorf, Heinrich-Heine-University Düsseldorf, Düsseldorf, Germany, ${ }^{3}$ Department of Nephrology and Medical Intensive Care, Charité-Universitätsmedizin Berlin, Berlin, Germany, ${ }^{4}$ Institute for Physiology and Pathophysiology, Johannes Kepler University Linz, Linz, Austria, ${ }^{5}$ Calciscon AG, Biel, Switzerland, ${ }^{6}$ German Centre for Cardiovascular Research (DZHK), Partner Site Berlin, Berlin, Germany
\end{abstract}

Patients with primary aldosteronism (PA) are more susceptible to cardiovascular disease and mortality than patients with primary hypertension. This is mostly attributed to excess production of aldosterone and its effects on the development of vascular injury. A novel functional test $\left(T_{50}\right)$ measures serum calcification propensity. Lower $T_{50}$-values predict higher cardiovascular risk. We investigated serum calcification propensity and vascular calcification in PA and resistant hypertension $(\mathrm{RH})$. $T_{50}$ measurement was performed in patients with PA $(n=66)$ and $\mathrm{RH}(n=28)$ at baseline and after 403 (279-640) and 389 (277-527) days of treatment. No significant differences in $T_{50}$-values were observed between the groups ( $371 \pm 65$ and $382 \pm 44$ min, in PA and RH group, respectively, $p>$ 0.05). However, higher aldosterone-to-renin ratios were associated with lower $T_{50}$-values in PA-patients $(r-0.282, p<0.05)$. Furthermore, lower $T_{50}$-values were associated with increased abdominal aortic calcification measured by Agatston score in PA ( $r-0.534$, $p<0.05$ ). In both, $\mathrm{PA}$ and $\mathrm{RH}$, higher atherosclerotic cardiovascular disease (ACSVD) scores $(r-0.403, p<0.05)$ and lower HDL $(r 0.469, p<0.05)$ was related to lower $\mathrm{T}_{50^{-}}$ values in a linear regression model. Adrenalectomy or medical treatment did not increase $T_{50}$-values. In comparison to patients with stable $T_{50}$-values, PA patients with a decrease in $T_{50}$ after intervention had higher serum calcium concentrations at baseline (2.24 \pm 0.11 vs. $2.37 \pm 0.10 \mathrm{mmol} / \mathrm{l}, p<0.05)$. This decline of $T_{50}$-values at follow-up was also associated with a decrease in serum magnesium $(-0.03 \pm 0.03 \mathrm{mmol} / \mathrm{l}, p<0.05)$ and an increase in phosphate concentrations $(0.11 \pm 0.11 \mathrm{mmol} / \mathrm{l}, p<0.05)$. Resistant hypertension patients with a decrease in $T_{50}$-values at follow-up had a significantly lower eGFR at baseline. In summary, these data demonstrate an association between a high aldosterone-to-renin ratio and low $T_{50}$-values in PA. Moreover, lower $T_{50}$-values 
are associated with higher ACSVD scores and more pronounced vascular calcification in PA. Thus, serum calcification propensity may be a novel modifiable risk factor in PA.

Keywords: aldosterone, primary aldosteronism, hypertension, vascular calcification, serum calcification propensity

\section{INTRODUCTION}

Primary aldosteronism (PA), one of the most common causes of secondary hypertension, is the consequence of the excessive autonomous production of aldosterone either by an aldosterone producing adenoma (APA) or by bilateral hyperplasia (1). Increased mineralocorticoid-receptor activation is associated with hypertension and cardiovascular aging $(2,3)$. Patients with PA develop and die more often from cardiovascular diseases than patients with primary hypertension (4). A contributing factor could be aldosterone-induced vasculopathy and vascular calcification, promoting the development of arterial stiffness (59). Vascular calcification has been discussed as an important cardiovascular risk factor, as the presence of vascular calcification was associated with an up to four times increased cardiovascular mortality in a meta-analysis (10).

Vascular calcification is a multifactorial and regulated process, augmented by active mechanisms involving vascular smooth muscle cells (11). These cells may undergo an osteogenic reprogramming upon exposure to calcification-stimuli and subsequently promote an extracellular environment favoring mineralization (11). Elevated aldosterone concentrations augment osteogenic reprogramming and calcification of vascular smooth muscle cells (3,12-14). Furthermore, excessive mineralocorticoid receptor (MR) activation has been associated with endothelial dysfunction, activation of myeloid cells, and vascular inflammation as well as other vascular alterations, which may promote vascular calcification $(13,15-17)$. Accordingly, recent studies have shown that patients with PA have more pronounced vascular calcification than age matched controls with essential hypertension $(\mathrm{EH})(18,19)$. Ectopic vascular calcification is closely associated with dysregulated phosphate homeostasis. Phosphate can precipitate with calcium, a process prevented by systemic and local calcification inhibitors (20). An important role in the prevention of ectopic calcification is attributed to formation of calciprotein particles (CPP) to clear calcium-phosphate ion clusters from blood and tissues (21). The insufficient clearance and maturation of spontaneously formed primary CPPs toward a secondary larger form with crystalline core has been termed as "mineral stress." Secondary CPPs induce osteogenic reprogramming and calcification of vascular smooth muscle cells, a process which is suspected as key culprit in the promotion of vascular calcification by phosphate (21). The performance of this functional system can be assessed in serum samples by the $T_{50}$ calcification propensity test (22). The $T_{50}$ test determines the half maximal transformation time $\left(T_{50}\right)$ of primary CPPs to the secondary insoluble CPPs, where lower $\mathrm{T}_{50}$ is associated with increased serum calcification propensity (22). Thus, the presence of anti-calcific factors prolongs this time, while reduced "anti-calcific defense" shortens this time. Factors modifying this assay are e.g., calcium, phosphate, magnesium, and anti-calcific proteins such as Fetuin-A (22), but further currently unknown determinants may be involved in the test results. As an overall functional assay, the results could be interpreted as how prone an individual patient serum is toward calcification. The importance of serum calcification propensity was confirmed in general (23), pre-dialysis (24), dialysis (25), kidney transplant populations (26) where it outperformed the traditional risk factors.

Since elevated aldosterone concentrations promote phosphate-induced vascular calcification (12), we investigated whether PA patients are prone to worse serum calcification propensity. Therefore, we measured serum calcification propensity $\left(\mathrm{T}_{50}\right)$ in patients with PA. To accurately elucidate the role of aldosterone, we compared PA patients to blood pressure matched patients with resistant hypertension (RH) with no history of PA. Moreover, by measuring $\mathrm{T}_{50}$ at the diagnosis and 1 year after treatment initiation we were able to present intra-individual changes in this population.

\section{METHODS}

\section{Study Population}

A total of $66 \mathrm{PA}$ patients and 28 age, gender, blood pressure matched patients with $\mathrm{RH}$ were recruited for this observational prospective study. The study was approved by the local ethics committee (Study numbers: 3848 and 3919) and carried out in accordance with the Declaration of Helsinki. All patients provided written informed consent to participate in the study.

All patients enrolled into the study underwent examinations according to previously published guidelines in order to exclude or confirm secondary causes of hypertension (27). Patients with abnormal aldosterone renin ratio (ARR) after discontinuation of interacting antihypertensive drugs were further investigated and received an intravenous salt loading test to confirm the diagnosis PA. To determine whether unilateral or bilateral adrenal gland involvement is responsible for the excessive aldosterone production, all patients underwent selective adrenal vein sampling and imaging of the adrenal glands either by CTscan or MRI. Patients with unilateral masses in the imaging and unilateral autonomous hormone production were advised to undergo adrenalectomy. In such cases, the diagnosis of an APA was confirmed histologically. Patients who showed lateralization in the selective adrenal vein sampling but were not operated, were referred to as unilateral hyperplasia (ULH) and treated with MRA. Patients with bilateral adrenal hyperplasia were treated with MRA. According to the ESH/ESC guidelines (28), patients were defined having $\mathrm{RH}$ if under the prescription of three different antihypertensive drugs including a diuretic hypertensive blood pressure values were observed. In addition, these patients 
received examinations in order to rule out secondary causes of hypertension. Of note, due to the often asymptomatic course of hypertension and the prolonged diagnosis of PA and $\mathrm{RH}$, we do not have the exact date when our patients developed PA or RH.

Demographic data such as age, gender, body weight, the etiology of PA, and leading comorbidities, were collected at the time of the study entry from medical records. Blood samples were drawn at study entry and at the follow up visit 12 months after treatment initiation which in the case of PA was adrenalectomy or drug therapy with MR blocker. Resistant hypertension patients received adjustments in antihypertensive treatment. At both visits patients received $24 \mathrm{~h}$ blood pressure monitoring. The measurements were performed using Mobilograph PWA system (IEM GmbH, Stolberg, Germany). During the day blood pressure was measured every $15 \mathrm{~min}$ whereas at night every $30 \mathrm{~min}$. The size of the cuff was chosen individually. Laboratory parameters such aldosterone, renin, ARR, electrolytes, creatinine, albumin, C-reactive protein were assessed using standard methods.

\section{Cardiovascular Risk Score}

Risk of major cardiovascular complications such as heart disease and stroke was assessed using atherosclerotic cardiovascular disease (ACSVD) score which was proposed by the American College of Cardiology and the American Heart Association (ACC/AHA) in 2013 (29). Calculator includes parameters as age, gender, race, blood pressure values and treatment situation, concentrations of total cholesterol, and high density lipoprotein (HDL), smoking status, history of diabetes. It is important to note, that ACSVD score is validated for 40-79 years old patients without a history of heart attack or stroke. The risk is given as percentages. Values between 5 and $7.5 \%$ describe borderline risk, $7.5-20 \%$ intermediate risk whereas values above $20 \%$ are associated with high risk for major cardiovascular events. For further analysis patients were divided into two groups-the ones with low risk and the ones with ACSVD score above $7.5 \%$ representing intermediate and high risk pattern.

\section{Calcification Propensity Measurement $\left(T_{50}\right)$}

Fasting blood samples were drawn from a peripheral vein in vacuum tubes and immediately centrifuged at 3,000 rpm for $15 \mathrm{~min}$ at ambient temperature. The extracted serum was stored in aliquots and was frozen at $-80^{\circ} \mathrm{C}$ until further use. Calcification propensity score was determined as the half maximal transformation time from primary to secondary CPP$\mathrm{T}_{50}$ at the Calciscon Laboratory in Switzerland (22), which was blinded for the patients.

\section{Measurement of Vascular Calcification in Computer Tomography}

At the study entry patients diagnosed with PA underwent either an unenhanced abdominal CT scan or MRI in order to confirm adrenal adenoma or hyperplasia. Available CT scans were assessed using Syngo.via Calcium Scoring software (Siemens Medical Solutions, USA) which is originally used to evaluate the extent of coronary calcification (30). Similar to the evaluation of coronary arteries, calcified areas with density above 130 $\mathrm{HU}$ (Hounsfield units) of aorta from diaphragm to bifurcation were marked by two independent observers with experience in computed tomography and calcium scoring, which enabled the assessment of calcification volume, equivalent mass, peak density, and Agatston score as described previously (31). Agatston score is a software tool based on the weighted density score given to the highest attenuation value multiplied by the calcified area.

\section{Statistical Analysis}

Statistical analysis was performed using SPSS version 23 (SPSS Inc., Chicago, USA) and Graph Prism 5.3 (GraphPad Software, San Diego, USA). Continuous data are expressed as mean \pm standard deviation (SD) or median (interquartile ranges expressed as two numbers, Q1-Q3, respectively) whereas categorical data are expressed as number (percentage). ShapiroWilk test was used to test if collected data is normally distributed. The difference among groups was evaluated using chi-square, t-test, or Mann Whitney test where appropriate. In order to compare the means between entry visit and follow up, paired $t$-test, or Wilcoxon signed rank test was performed. Linear regression was used for indicating variables associated with $\mathrm{T}_{50}$. In some cases because of violated homoscedasticity a weighted least squares (WLS) regression was used. Variables having significant effect on $\mathrm{T}_{50}$ in univariate linear regression were included into multivariate analysis. Receiver operating characteristic (ROC) curve and Youden test was used to determine $\mathrm{T}_{50}$ cutoff values for moderate to severe abdominal aortic calcification risk. A $p$-value $<0.05$ was considered statistically significant.

\section{RESULTS}

\section{Study Population}

Baseline characteristics of patients diagnosed with PA and $\mathrm{RH}$ are presented in Table $\mathbf{1}$. No differences in gender, age, blood pressure, renal function, and cholesterol levels were present between the groups. By definition, patients with PA had significantly higher aldosterone concentration and ARR levels whereas renin production was markedly reduced $(p<0.05)$. Cardiovascular risk assessment using ACSVD score was lower among PA patients (median score 9.6\% among PA group and $24.9 \%$ among $\mathrm{RH}$ group, $p<0.05$ ). This effect could be attributed to the fact that beside high blood pressure, these patients did not have any other factors such as diabetes or smoking history accounting for higher cardiovascular risk. Serum mineral parameters appeared well-controlled and within populationbased reference values within the studied groups. $\mathrm{T}_{50}$-values at study entry among patients with PA were slightly lower compared to ones observed in RH group, $371 \pm 65 \mathrm{~min}$ and $382 \pm 44 \mathrm{~min}$, $p>0.05$ respectively (Table $\mathbf{1}$ ).

\section{Influence of Clinical and Biochemical Factors on Calcification Propensity}

In order to assess the relationship between $\mathrm{T}_{50}$ and various variables, a linear regression model was established (Table 2). Analyzing the whole cohort as a population for difficult-to-treat hypertension, higher ACVSD score $(r-0.403, p<0.05)$ and lower HDL $(r 0.469, p<0.05)$ were related to lower $\mathrm{T}_{50}$-values. 
TABLE 1 | Baseline characteristics of study groups.

\begin{tabular}{|c|c|c|c|}
\hline & All patients & PA & RH \\
\hline Male: Female & $1.8: 1$ & $1.8: 1$ & 1.8:1 \\
\hline Age, years & $54.6 \pm 11.7$ & $53.5 \pm 12.4$ & $58.0 \pm 11.2$ \\
\hline \multicolumn{4}{|l|}{ Diagnosis, $n$ (\%) } \\
\hline APA/ULH & $36(38.3 \%)$ & $36(54.5 \%)$ & $0(0.0 \%)^{\star \star \star}$ \\
\hline BLH & $26(27.7 \%)$ & $26(39.4 \%)$ & $0(0.0 \%)^{\star \star \star}$ \\
\hline Unclassified & $4(4.2 \%)$ & $4(6.1 \%)$ & $0(0.0 \%)^{\star \star \star}$ \\
\hline $\mathrm{RH}$ & $28(29.8 \%)$ & $0(0.0 \%)$ & $28(100 \%)^{\star \star \star}$ \\
\hline Systolic BP, mmHg & $155 \pm 19$ & $154 \pm 11$ & $156 \pm 21$ \\
\hline Diastolic BP, mmHg & $90 \pm 9$ & $88 \pm 8$ & $91 \pm 10$ \\
\hline ACSVD score, $\%$ & $13.9(6.6-24.5)$ & $9.6(4.7-16.8)$ & $24.9(17.5-29.9)^{\star}$ \\
\hline Aldosterone, ng/l & $148.7(98-223.7)$ & $187.3(119-241)$ & $99(42-148)^{\star \star \star}$ \\
\hline Renin, $\mathrm{pg} / \mathrm{ml}$ & $2.5(1.6-7.5)$ & $1.9(1.2-2.8)$ & $11(4.4-59)^{\star \star \star}$ \\
\hline ARR & $61.1(22.1-108)$ & $85.3(52.4-134.4)$ & $4.6(0.9-22.9)^{\star \star \star}$ \\
\hline ARR at follow up & $8(2.2-26.2)$ & $8.7(2.5-30.3)$ & $4.0(0.9-15.4)$ \\
\hline Creatinine, mg/dl & $0.9(0.8-1.1)$ & $0.9(0.8-1.1)$ & $0.9(0.8-1.3)$ \\
\hline eGFR, ml/min/1.73 m² & $80.5(69.5-95.5)$ & $82(72.7-95.5)$ & 74.5 (54.5-96.5) \\
\hline Calcium, mmol// & $2.31 \pm 0.1$ & $2.33 \pm 0.1$ & $2.30 \pm 0.1$ \\
\hline Phosphate, mmol// & $0.99 \pm 0.2$ & $0.97 \pm 0.3$ & $1.01 \pm 0.2$ \\
\hline Magnesium, mmol/l & $0.84 \pm 0.1$ & $0.83 \pm 0.1$ & $0.86 \pm 0.1$ \\
\hline Triglyceride, mg/dl & $126(95-184)$ & $127(96-183)$ & 119 (93-206) \\
\hline $\mathrm{HDL}, \mathrm{mg} / \mathrm{dl}$ & 47 (38-61) & $49(41-61)$ & $45(37-57)$ \\
\hline Albumin, g/dl & $4.4 \pm 0.3$ & $4.4 \pm 0.3$ & $4.4 \pm 0.5$ \\
\hline CRP, mg/dl & $0.3(0.2-0.6)$ & $0.3(0.2-0.5)$ & $0.4(0.3-1.1)^{\star}$ \\
\hline $\mathrm{HbA} 1_{\mathrm{C}}, \%$ & $5.6(5.2-6.1)$ & $5.4(5.1-5.8)$ & $5.8(5.6-6.4)^{\star}$ \\
\hline$T_{50}, \min$ & $372 \pm 59$ & $371 \pm 65$ & $382 \pm 44$ \\
\hline $\mathrm{T}_{50}$ at follow up, min & $359 \pm 54$ & $354 \pm 52$ & $367 \pm 56$ \\
\hline
\end{tabular}

PA, primary aldosteronism; $R H$, resistant hypertension; $A P A$, aldosterone producing adenoma; ULH, unilateral adrenal hyperplasia; $B L H$, bilateral adrenal hyperplasia; $B P$, blood pressure; ACSVD, atherosclerotic cardiovascular disease score; ARR, aldosterone renin ratio; eGFR, estimated glomerular filtration rate; HDL, high density lipoprotein; CRP, C-reactive protein; HDA1C, glycosylated hemoglobin; $T_{50}$, calcification propensity. Dichotomous data are presented as percentages whereas continuous data as means \pm SD or median (Q1-Q3).

"Represent significant difference between the groups with $p<0.05,{ }^{\text {t"tw }} p<0.001$ using t-test, chi-square or Mann Whitney test.

Similar associations were observed analyzing study groups separately. Higher cardiovascular risk score was associated with lower $\mathrm{T}_{50}$-value in both groups however statistical significance was met only in the PA group $(r-0.483, p<0.05)$. In the $\mathrm{RH}$ group an inverse negative relationship between phosphate $(r-0.422, p<0.05)$ and a positive relationship between HDL $(r$ 0.769, $p<0.05)$ concentration and $\mathrm{T}_{50}$ was observed.

At the time of diagnosis, ARR measurements for PA patients were performed after discontinuation of medications interacting with renin-angiotensin-aldosterone system. In PA patients, there was a significant negative relationship between ARR and $\mathrm{T}_{50}(r$ $-0.282, p<0.05)$ whereas among RH patients an opposite effect was observed $(r 0.397, p<0.05)$. As expected after the treatment, PA patients had normal ARR levels which were similar to those observed among RH patients (median 8.7 (2.5-30.3) and 4.0 (0.915.4) among PA and RH patients, respectively, $p>0.05)$. At
TABLE 2 | Univariate linear regression assessing the relationship between $T_{50}$ measured at the study entry and various variables.

\begin{tabular}{|c|c|c|c|c|c|c|}
\hline \multirow[t]{2}{*}{ Variable } & \multicolumn{2}{|c|}{ All patients } & \multicolumn{2}{|c|}{ PA } & \multicolumn{2}{|c|}{$\mathbf{R H}$} \\
\hline & $\beta$ & $p$ & $\beta$ & $p$ & $\beta$ & $p$ \\
\hline Age & -0.033 & 0.775 & -0.153 & 0.276 & 0.192 & 0.337 \\
\hline Gender & 0.053 & 0.637 & 0.093 & 0.506 & -0.054 & 0.786 \\
\hline Phosphate & -0.221 & 0.060 & -0.186 & 0.206 & -0.422 & 0.036 \\
\hline Calcium & 0.024 & 0.836 & 0.040 & 0.779 & 0.005 & 0.982 \\
\hline Magnesium & 0.111 & 0.361 & 0.044 & 0.778 & 0.255 & 0.209 \\
\hline Potassium & -0.178 & 0.115 & -0.248 & 0.077 & -0.304 & 0.115 \\
\hline Creatinine & -0.014 & 0.903 & 0.035 & 0.806 & -0.230 & 0.258 \\
\hline eGFR & -0.009 & 0.936 & -0.019 & 0.890 & 0.176 & 0.370 \\
\hline Albumin & 0.111 & 0.359 & 0.160 & 0.279 & 0.048 & 0.831 \\
\hline HDL & 0.469 & $<0.001$ & 0.259 & 0.075 & 0.769 & $<0.001$ \\
\hline Triglyceride & -0.030 & 0.796 & -0.043 & 0.764 & -0.146 & 0.478 \\
\hline CRP & -0.081 & 0.485 & -0.258 & 0.070 & -0.045 & 0.823 \\
\hline ACSVD & -0.403 & 0.004 & -0.483 & 0.002 & -0.138 & 0.685 \\
\hline Aldosterone & -0.079 & 0.487 & -0.133 & 0.342 & 0.281 & 0.155 \\
\hline ARR & -0.103 & 0.362 & -0.282 & 0.041 & 0.397 & 0.040 \\
\hline
\end{tabular}

PA, primary aldosteronism; $R H$, resistant hypertension; eGFR, estimated glomerular filtration rate; HDL, high density lipoprotein; CRP, C-reactive protein; ACSVD, atherosclerotic cardiovascular disease score; $A R R$, aldosterone renin ration. Significance with $p<0.05$. The bold values emphasize variables having significant effect on $T_{50}$.

follow up visit, ARR was positively correlated to $\mathrm{T}_{50}(r$ 0.441, $p$ $<0.05)$.

Factors which showed significant relationship with $\mathrm{T}_{50}$ in univariate analysis were further analyzed using multivariate regression model. High phosphate concentration remained related to lower $\mathrm{T}_{50}$ when analyzing whole study population (Supplementary Table 1). There was a significant negative relationship between ARR and $\mathrm{T}_{50}$ in PA $(r-0.365, p<0.05)$. High HDL concentration and high normal ARR were associated with higher $\mathrm{T}_{50}$-values among $\mathrm{RH}$ patients in multivariate linear regression model (Supplementary Table 1).

\section{Assessment of Vascular Calcification}

Eighteen PA patients with available $\mathrm{T}_{50}$-values received abdominal CT scan which enabled the assessment of vascular calcification. There was a negative relationship between $T_{50^{-}}$ value and the extent of vascular calcification within abdominal aorta expressed as equivalent mass $(r-0.557, p<0.05)$ and as Agatston score $(r-0.534, p<0.05$, as shown in Figure 1). In this patient group, $\mathrm{T}_{50}$-values $<338 \mathrm{~min}$ had a $69.2 \%$ sensitivity and an $87.5 \%$ specificity (Youden index 0.567 ) to identify patients with an Agatston score higher than 100 which indicates moderate or severe abdominal aortic calcification.

\section{Follow-Up}

Primary aldosteronism group was followed-up for a median of 403 (279-640) days whereas RH group for 389 (277-527) days, $p>0.05$. Following treatment, mean $\mathrm{T}_{50}$-values were lower in comparison to baseline values in both study groups $(371 \pm 65$ vs. $354 \pm 52 \mathrm{~min}, p<0.05$ among PA patients and $382 \pm$ 


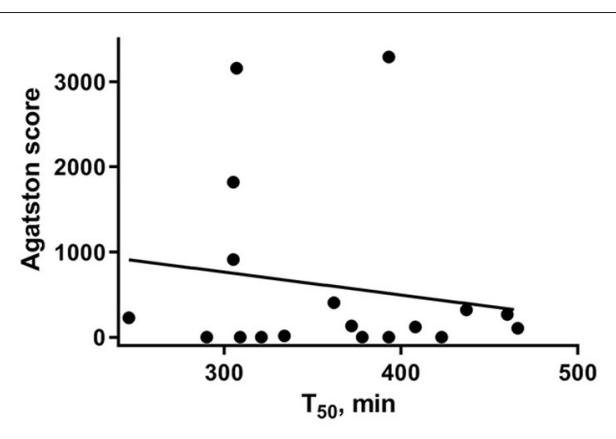

FIGURE 1 | Linear association between calcification propensity measured as $T_{50}(X$ axis) and Agatston score $(Y$ axis), representing the extent of vascular calcification observed in unenhanced CT imaging of abdominal aorta.

44 vs. $367 \pm 56 \mathrm{~min}, p>0.05$ among $\mathrm{RH}$ group as shown in Supplementary Table 2). To investigate the alteration of $\mathrm{T}_{50}$, we divided our patients in two groups according the $\mathrm{T}_{50}$ change over the time. Patients with stable or higher $\mathrm{T}_{50}$-values over the follow up period were described as stable whereas patients with decrease in $\mathrm{T}_{50}$ of more than $5 \%$ compared to the initial value were described as decrease group. The distribution of $\mathrm{T}_{50}$ change among both groups is demonstrated in Figure 2. Fifty-four percent of patients had stable or increasing $\mathrm{T}_{50}$-values following the treatment. Of note, $\mathrm{T}_{50}$-values did not differ between PA patients treated either by adrenalectomy or by MR antagonist (data not shown).

As a next step, factors associated with $\mathrm{T}_{50}$ change were analyzed. In the PA group, patients with high normal serum calcium concentration at entry tended to have a decrease in $\mathrm{T}_{50}$. Mean baseline calcium in $\mathrm{T}_{50}$ decrease group was $2.37 \pm 0.10$ $\mathrm{mmol} / \mathrm{l}$ whereas patients with stable $\mathrm{T}_{50}$-values had lower mean calcium concentration, $2.24 \pm 0.11 \mathrm{mmol} / \mathrm{l}$, respectively, $p<$ 0.05 . Additionally, PA patients in the decreased group showed a significant decline in serum magnesium concentration $(-0.03 \pm$ $0.03 \mathrm{mmol} / \mathrm{l}$ ) and a significant increase in serum phosphate levels $(0.11 \pm 0.11 \mathrm{mmol} / \mathrm{l})$ over the follow up period.

In the RH group above mentioned variables did not differ between the stable and decrease $\mathrm{T}_{50}$ groups. However, in the decrease $\mathrm{T}_{50}$ group, significantly lower baseline eGFR values were observed compared to the stable RH group (eGFR 61 (31-86) vs. $\left.92(77-104) \mathrm{ml} / \mathrm{min} / 1.73 \mathrm{~m}^{2}, p<0.05\right)$. Of note, a decline in renal function over the follow-up period was associated with a decrease in $\mathrm{T}_{50}$, however the statistical significance was not met (Table 3).

\section{DISCUSSION}

The present study explored for the first time the calcification propensity among patients with PA. Here, we show that every ARR increase of 10 was related to $2.8 \mathrm{~min}$ reduction in $\mathrm{T}_{50^{-}}$ values among patients with PA. Secondly, patients with lower $\mathrm{T}_{50}$-values had higher ACSVD scores and more pronounced vascular calcification in CT scans. Thirdly, in contrast to our initial hypothesis, normalization of aldosterone concentration either by the surgery or MR blocker therapy did not result in higher $\mathrm{T}_{50}$-values.

Serum calcification propensity might be a clinically useful tool to predict and monitor vascular calcification and cardiovascular risk (21). The $\mathrm{T}_{50}$ test depends on calcification promoters and inhibitors present in the serum and is associated with cardiovascular mortality (23). Several studies have indicated that $\mathrm{T}_{50}$-values decrease in chronic renal failure or diabetes $(23,32)$. $\mathrm{T}_{50}$-values of patients on dialysis are lower than in pre-dialysis patient, and associate with clinical outcomes (24-26). On the other hand, longer duration of CPP maturation determined as higher $\mathrm{T}_{50}$-time has been associated with better clinical outcomes, and could be considered an improved calcification propensity with reduced risk for ectopic calcification (23). In the present study, mean $\mathrm{T}_{50}$-values among patients with $\mathrm{PA}$ were $371 \pm 65 \mathrm{~min}$ and among $\mathrm{RH}$ patients $382 \pm 44 \mathrm{~min}$, respectively (23). The current investigations on $\mathrm{T}_{50}$ are limited by the absence of a healthy control group, and alterations of $\mathrm{T}_{50}$ in $\mathrm{PA}$ compared to healthy conditions require further study. We cannot rule out other determinants influencing the serum calcification propensity in $\mathrm{RH}$ patients, which are not primarily mediated by elevated aldosterone concentration. In patients with arterial hypertension, lower $\mathrm{T}_{50}$-values were observed as compared to healthy controls (33). In our cohort, no difference in $\mathrm{T}_{50}$-values were detected between the PA and $\mathrm{RH}$ groups, although RH patients had a higher cardiovascular risk score. Based on these observations, it could be speculated that higher cardiovascular risk would be translated into lower $\mathrm{T}_{50}$-values. In theory, as these $\mathrm{T}_{50}$-values did not differ between $\mathrm{PA}$ and $\mathrm{RH}$ patients, these results could indirectly suggest an additional effect of aldosterone on calcification propensity as a novel independent non-traditional cardiovascular risk factor (23). Indeed, in patients with PA, the ARR was inversely related to endogenous calcification inhibitory mechanisms, as high ARRs were related to lower $\mathrm{T}_{50}$-values.

According to results from the general population and patients with impaired renal function, lower $\mathrm{T}_{50}$-values are consistently related to higher cardiovascular mortality $(23,25,26)$. Due to the small population and the short follow-up, we did not analyze cardiovascular mortality. Instead, we addressed the cardiovascular morbidity risk by using the well-established ACSVD score which showed a significant correlation between high ACSVD score and low $\mathrm{T}_{50}$-values, especially in patients with PA. Long term follow up studies are in need to confirm the increased cardiovascular risk related to low $\mathrm{T}_{50}$-values. In addition to the ACSVD score, other laboratory parameters which are traditionally related to higher cardiovascular morbidity such as high phosphate and lower HDL concentration were also significantly associated with lower $\mathrm{T}_{50}$-values $(23,25,26,33)$.

In order to assess the clinical impact of the $\mathrm{T}_{50}$ test in patients with PA and to determine its relationship with aldosterone and vascular calcification, we analyzed the available CT scans from patients with PA which were performed at the time of diagnosis. We found that $\mathrm{T}_{50}$-values correlated with the extent of vascular calcification of the aorta. Patients with low $\mathrm{T}_{50^{-}}$ values showed increased equivalent calcification mass and higher abdominal Agatston score. Previous studies in patients with 
PA group

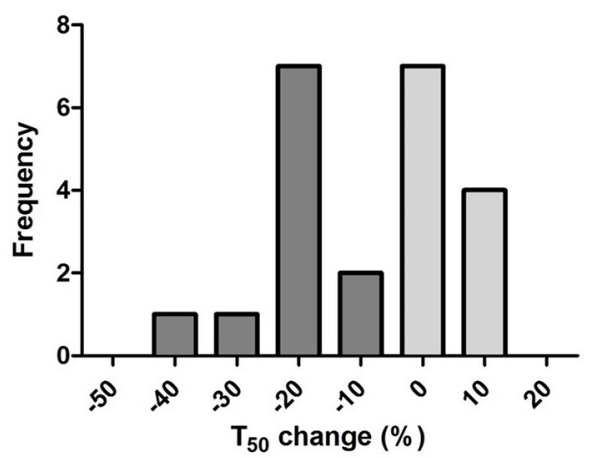

RH group

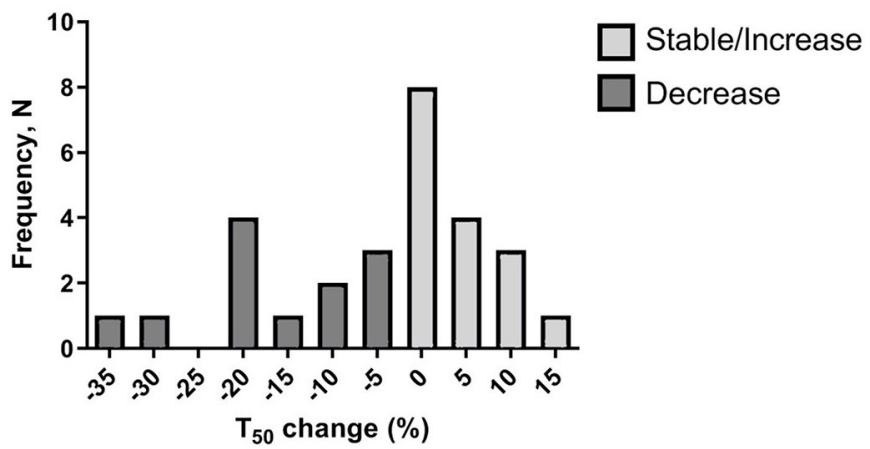

FIGURE 2 | Histogram representing $T_{50}$ changes among patients with PA and RH. Patients with stable or higher $\mathrm{T}_{50}$-values over the follow up period were described as stable (gray colored columns) and the ones with a decrease in $T_{50}$ more than $5 \%$ compared to the initial value were described as decrease group (dark gray colored columns). $Y$ axis represents the number of patients for each change group.

TABLE 3 | $T_{50}$ changes among the study groups during follow-up.

\begin{tabular}{|c|c|c|c|c|}
\hline \multirow[t]{2}{*}{ Variable } & \multicolumn{2}{|c|}{ PA group } & \multicolumn{2}{|c|}{ RH group } \\
\hline & Stable & Decrease & Stable & Decrease \\
\hline Number of patients, $N$ & 11 & 11 & 16 & 12 \\
\hline Age, years & $50.6 \pm 8.3$ & $55.5 \pm 11.5$ & $56.8 \pm 12.9$ & $59.5 \pm 12.0$ \\
\hline Male:Female & $1: 1.2$ & $1: 0.8$ & $1: 0.8$ & $1: 0.3$ \\
\hline Phosphate, mmol// & $1.02 \pm 0.13$ & $0.97 \pm 0.25$ & $0.99 \pm 0.14$ & $1.08 \pm 0.19$ \\
\hline$\Delta$ Phosphate, $\mathrm{mmol} / \mathrm{l}$ & $-0.04 \pm 0.15$ & $0.11 \pm 0.11^{\star}$ & $0.13 \pm 0.15$ & $0.22 \pm 0.38$ \\
\hline Calcium, mmol/l & $2.24 \pm 0.11$ & $2.37 \pm 0.10^{\star}$ & $2.29 \pm 0.11$ & $2.27 \pm 0.08$ \\
\hline$\Delta$ Calcium, mmol/l & $0.07 \pm 0.07$ & $0.09 \pm 0.12$ & $0.04 \pm 0.14$ & $0.08 \pm 0.13$ \\
\hline Magnesium, mmol/l & $0.80 \pm 0.09$ & $0.83 \pm 0.10$ & $0.82 \pm 0.08$ & $0.89 \pm 0.08$ \\
\hline$\Delta$ Magnesium, mmol/l & $0.03 \pm 0.04$ & $-0.03 \pm 0.03^{\star \star}$ & $0.01 \pm 0.07$ & $-0.03 \pm 0.09$ \\
\hline eGFR, ml/min/1.73 m² & $89(75-92)$ & $95(88-103)$ & $92(77-104)$ & $61(31-86)^{\star \star}$ \\
\hline$\Delta$ eGFR, $\mathrm{ml} / \mathrm{min} / 1.73 \mathrm{~m}^{2}$ & $-11(-11$ to 4$)$ & $-22(-28$ to -6$)$ & $-4(-9$ to 0.5$)$ & $-4(-7$ to -1.5$)$ \\
\hline Albumin, g/dl & $4.4 \pm 0.4$ & $4.6 \pm 0.3$ & $4.3 \pm 0.4$ & $4.4 \pm 0.4$ \\
\hline $\mathrm{HDL}, \mathrm{mg} / \mathrm{dl}$ & $58(41-66)$ & $58(47-69)$ & $51(40-68)$ & $37(35-48)$ \\
\hline Triglyceride, mg/dl & 139 (73-204) & $126(111-145)$ & $116(91-171)$ & $132(102-251)$ \\
\hline CRP, mg/dl & $0.2(0.1-0.3)$ & $0.4(0.3-0.8)$ & $0.3(0.3-0.8)$ & $1.0(0.3-1.9)$ \\
\hline ACSVD score, \% & $6.6(3.7-8.9)$ & $13.8(7.5-16.6)$ & 27 (25.1-29) & $24.2(17.5-25)$ \\
\hline Aldosterone, ng/l & $186(119-226)$ & 103 (83.7-222) & 76.5 (35.7-152) & $127(46-148)$ \\
\hline ARR & 93.8 (42.5-119) & $53.4(31-101.1)$ & $4.4(0.9-25.8)$ & $4.6(0.4-14.4)$ \\
\hline
\end{tabular}

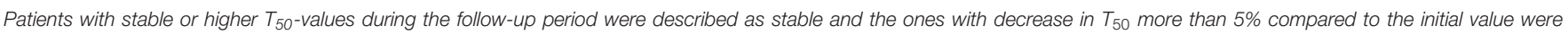
described as decrease group. PA, primary hyperaldosteronism; RH, resistant hypertension; $\Delta$ change between entry and follow up visit; eGFR, estimated glomerular filtration rate; HDL,

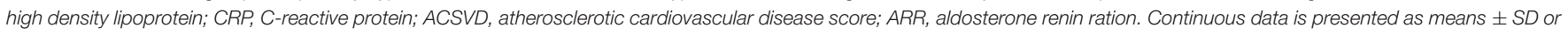
median (Q1-Q3).

${ }^{*} p<0.05,{ }^{* *} p<0.01$, difference within the study group (PA or RH) using t-test, chi-square, or Mann-Whitney test.

chronic kidney disease have shown an association of $\mathrm{T}_{50}$ with coronary calcification progression (34) and aortic stiffness (24) therefore the present study provides additional information on clinical impact of low $\mathrm{T}_{50}$-values among these patients. Various clinical and experimental studies highlighted the important role of aldosterone in the development of vascular calcification (13, 35,36 ). High aldosterone concentrations are associated with subclinical coronary atherosclerosis and mortality in general population (37) and in patients with PA an early development of vascular calcification is observed (18). The use of MRA on the other hand may ameliorate vascular calcification $(3,38)$. According to experimental studies, aldosterone exerts its effects at least partly by binding to the mineralocorticoid-receptor in vascular smooth muscle cells (39). Multiple experimental studies show that elevated aldosterone concentration promotes the transition of vascular smooth muscle cells toward an osteogenic phenotype and thereby promotes calcification (40). However, the current observations do not provide clear evidence that 
these effects of aldosterone may be reflected in a worsened serum calcification propensity of PA patients as compared to $\mathrm{RH}$ patients. A further comparison with healthy patients would be necessary to clearly differentiate alterations of $\mathrm{T}_{50}$-time in these collectives. Furthermore, in the present study, treatment of PA patients either by adrenalectomy or by medical treatment with MR antagonists did not increase but rather decrease $\mathrm{T}_{50}$, while a recent study performed in hemodialysis patients has shown a slight increase of $\mathrm{T}_{50}$ under spironolactone treatment (41). Hypothetically, other systemic and renal effects of PA might indirectly compensate for more direct effects of aldosterone on calcification propensity, which could be relevant for the discrepancy between MRA effects in these populations. The different level of MR activation and therapeutic inhibition, as well as mean aldosterone concentrations or prolonged effects of aldosterone in PA patients in the absence of chronic kidney disease might play a role on calcification propensity. In addition, aldosterone-independent activation of the MR and modulation of its activity may be especially relevant in uremic conditions $(42,43)$.

Most studies on $\mathrm{T}_{50}$ were based on the evaluation of $\mathrm{T}_{50}$ at a single time point, and less information on longitudinal alterations of $\mathrm{T}_{50}$ are available. Recent observations showed that the decrease in $\mathrm{T}_{50}$ from $246 \pm 64$ to $190 \pm 68 \mathrm{~min}$ in 2 years among hemodialysis patients was an independent risk factor for mortality in this cohort (44). On the other hand, longer maturation of CPPs or higher $\mathrm{T}_{50}$ would translate into improved calcification propensity. As described above, due to short follow up we were not able to evaluate the mortality risk. Since prolongation of $\mathrm{T}_{50}$-time might be a therapeutic target, we aimed to identify factors determining $\mathrm{T}_{50}$ change over time in our population. First, in PA patients, higher calcium concentration at study entry was related to decrease in $T_{50}$ during the follow up period. Although calcium concentration stayed within normal range, it had a significant negative effect on calcification propensity. The relationship between aldosterone and calcium is complex. High aldosterone levels induce calciuria by activating calcium transport in renal tubuli. This effect causes hypocalcemia which further activates PTH secretion to compensate this mechanism (45-48). Moreover, higher normal calcium concentration could be explained by chronic vitamin D supplementation. Unfortunately, we were not able to rule out the effect of PTH concentration or vitamin D supplementation on calcium levels and $\mathrm{T}_{50}$ in these patients. Secondly, a decrease in magnesium concentration as low as $-0.3 \pm 0.3 \mathrm{mmol} / \mathrm{l}$ had a significant effect on $\mathrm{T}_{50}$ reduction in patients with PA. Magnesium counteracts the osteogenic effects of calciumphosphate on vascular smooth muscle cells and reduces vascular smooth muscle cell calcification $(49,50)$. There is growing evidence indicating that low normal magnesium concentration or lower dietary intake are associated with higher cardiovascular risk (51-54). Magnesium supplementation in turn is associated with beneficial effects on serum calcification propensity. An increment of $0.2 \mathrm{mmol} / \mathrm{l}$ was able to prolong $\mathrm{T}_{50}$ for $51 \pm$ $15 \mathrm{~min}$ for healthy people and $44 \pm 13 \mathrm{~min}$ for dialysis patients $(55,56)$. The effect of aldosterone on magnesium handling is still incompletely understood (57). Since aldosterone may induce magnesuria, the mechanisms underlying the observed associations in this cohort of PA patients appear elusive (57). Thirdly, in accordance with previous observations (58), we have observed that an increase in phosphate levels over the time was related to a lowering of $\mathrm{T}_{50}$. In addition, we have observed that patients with impaired renal function at baseline tended to have a decrease in $\mathrm{T}_{50}$ over the time, however a decrease in renal function during the follow up period did not significantly affect calcification propensity. This may be explained by the relatively short observation period. Taken together, longitudinal evaluation suggests, that $T_{50}$ is at least partially determined by calcium, phosphate and magnesium in PA-patients, which are known to contribute to $\mathrm{T}_{50}(22)$. To which extent altered mineral homeostasis due to renal and extrarenal effects of PA underly $\mathrm{T}_{50}$ in these patients requires further study. Although the current observations cannot rule out the involvement of other factors, control of these parameters could be a target for future study in order to prevent predisposition to calcification and cardiovascular risk in PA.

The present study has several strengths and limitations. Although we present $\mathrm{T}_{50}$ results from a cohort which is quite susceptible to cardiovascular mortality, our study population is small, with unequal sample size in the groups, observational and lacks a healthy control group, which might increase the possibility of biased associations. Furthermore, effects could be masked by scatter of measurements in such a small sample size. Due to short follow up we were not able to assess the cardiovascular mortality risk of these patients. On the other hand, the strength of the study is that it was performed in one center ensuring a strict work up and follow-up schedule, as well as strict and uniform pre-analytical sample processing. We have included vascular calcification measurements enabling the analysis of direct association of $\mathrm{T}_{50}$ with clinical outcome and intra-individual changes of $\mathrm{T}_{50}$ with regard to treatment.

To conclude, although higher aldosterone-renin-ratio was related to lower $\mathrm{T}_{50}$-values, normalization of $\mathrm{ARR}$ either by the surgery or medication was not associated with increased $\mathrm{T}_{50}$ in patients with PA, but rather a lower $T_{50}$ was observed at follow-up. Shortening of $\mathrm{T}_{50}$ over the observational period was associated with higher calcium levels, an increase in phosphate levels or decrease in magnesium concentrations in PA patients. Most importantly, serum calcification propensity was associated with ACSVD cardiovascular risk score and aortic calcification in PA patients. Further studies are warranted to confirm the current observations and whether therapies targeted to increase $\mathrm{T}_{50}$-time might benefit patients with PA.

\section{DATA AVAILABILITY STATEMENT}

The raw data supporting the conclusions of this article will be made available by the authors, without undue reservation.

\section{ETHICS STATEMENT}

The study was approved by the local Ethics Committee of the medical faculty of the Heinrich-Heine-University Düsseldorf (Study numbers: 3848 and 3919) and carried out in accordance with the Declaration of Helsinki. The patients/participants 
provided their written informed consent to participate in this study.

\section{AUTHOR CONTRIBUTIONS}

LS, LR, JV, and JS: conceptualization. AP, MK, KB, and MB: formal analysis. TK, CS, KB, and MK: investigation. MK, LR, JV, and JS: writing-original draft preparation. TK, KE, LS, AP, LR, JV, and JS: writing-review and editing. JV and JS: supervision. All authors contributed to the article and approved the submitted version.

\section{FUNDING}

This work was supported by Forschungskommission of the Medical Faculty, Heinrich-Heine-Universität

\section{REFERENCES}

1. Hannemann A, Wallaschofski H. Prevalence of primary aldosteronism in patient's cohorts and in population-based studies - a review of the current literature. Horm Metab Res. (2012) 44:157-62. doi: 10.1055/s-0031-1295438

2. Gorini S, Kim SK, Infante M, Mammi C, La Vignera S, Fabbri A, et al. Role of aldosterone and mineralocorticoid receptor in cardiovascular aging. Front Endocrinol. (2019) 10:584. doi: 10.3389/fendo.2019.00584

3. Lang F, Ritz E, Voelkl J, Alesutan I. Vascular calcification - is aldosterone a culprit? Nephrol Dial Transplant. (2013) 28:1080-4. doi: 10.1093/ndt/gft041

4. Meng Z, Dai Z, Huang K, Xu C, Zhang Y-G, Zheng H, et al. Long-term mortality for patients of primary aldosteronism compared with essential hypertension: a systematic review and meta-analysis. Front Endocrinol (Lausanne). (2020) 11:121. doi: 10.3389/fendo.2020.00121

5. Gekle M, Grossmann C. Actions of aldosterone in the cardiovascular system: the good, the bad, and the ugly? Pflugers Arch Eur J Physiol. (2009) 458:23146. doi: 10.1007/s00424-008-0616-0

6. Hundemer GL, Curhan GC, Yozamp N, Wang M, Vaidya A. Cardiometabolic outcomes and mortality in medically treated primary aldosteronism: a retrospective cohort study. Lancet Diabetes Endocrinol. (2018) 6:519. doi: 10.1016/S2213-8587(17)30367-4

7. Hanslik G, Wallaschofski H, Dietz A, Riester A, Reincke M, Allolio B, et al. Increased prevalence of diabetes mellitus and the metabolic syndrome in patients with primary aldosteronism of the German Conn's Registry. Eur J Endocrinol. (2015) 173:665-75. doi: 10.1530/EJE-15-0450

8. Reincke M, Fischer E, Gerum S, Merkle K, Schulz S, Pallauf $\mathrm{A}$, et al. Observational study mortality in treated primary aldosteronism: the German conn's registry. Hypertension. (2012) 60:618-24. doi: 10.1161/HYPERTENSIONAHA.112.197111

9. Struthers AD. Aldosterone-induced vasculopathy. Mol Cell Endocrinol. (2004) 217:239-41. doi: 10.1016/j.mce.2003.10.024

10. Rennenberg RJMW, Kessels AGH, Schurgers LJ, Van Engelshoven JMA, De Leeuw PW, Kroon AA. Vascular calcifications as a marker of increased cardiovascular risk: a meta-analysis. Vasc Health Risk Manag. (2009) 5:18597. doi: 10.2147/VHRM.S4822

11. Voelkl J, Egli-Spichtig D, Alesutan I, Wagner CA. Inflammation: a putative link between phosphate metabolism and cardiovascular disease. Clin Sci. (2021) 135:201-27. doi: 10.1042/CS20190895

12. Alesutan I, Voelkl J, Feger M, Kratschmar D V, Castor T, Mia S, et al. Involvement of vascular aldosterone synthase in phosphate-induced osteogenic transformation of vascular smooth muscle cells. Sci Rep. (2017) 7:2059. doi: 10.1038/s41598-017-01882-2

13. Voelkl J, Lang F, Eckardt KU, Amann K. Kuro-o M, Pasch A, et al. Signaling pathways involved in vascular smooth muscle cell
Düsseldorf (KS9772730) and the Deutsche Forschungsgemeinschaft (VO2259/2-1).

\section{ACKNOWLEDGMENTS}

The authors would like to thank all staff members of Nephrology department and Nephrology ambulance of University Clinics of Duesseldorf.

\section{SUPPLEMENTARY MATERIAL}

The Supplementary Material for this article can be found online at: https://www.frontiersin.org/articles/10.3389/fcvm. 2022.771096/full\#supplementary-material calcification during hyperphosphatemia. Cell Mol Life Sci. (2019) 76:2077-91. doi: 10.1007/s00018-019-03054-z

14. Voelkl J, Luong TTD, Tuffaha R, Musculus K, Auer T, Lian X. et al. SGK1 induces vascular smooth muscle cell calcification through NF-кB signaling. $J$ Clin Invest. (2018) 128:3024-40. doi: 10.1172/JCI96477

15. Epstein M, Freundlich M. The intersection of mineralocorticoid receptor (MR) activation and the FGF23 - Klotho cascade. A Duopoly that promotes renal and cardiovascular injury. Nephrol Dial Transplant. (2021) 2021:gfab254. doi: 10.1093/ndt/gfab254

16. Van Der Heijden CDCC, Deinum J, Joosten LAB, Netea MG, Riksen NP. The mineralocorticoid receptor as a modulator of innate immunity and atherosclerosis. Cardiovasc Res. (2018) 114:944-53. doi: 10.1093/cvr/cvy092

17. Man JJ, Lu Q, Elizabeth Moss M, Carvajal B, Baur W, Garza AE, et al. Myeloid mineralocorticoid receptor transcriptionally regulates p-selectin glycoprotein ligand-1 and promotes monocyte trafficking and atherosclerosis. Arterioscler Thromb Vasc Biol. (2021) 41:2740-55. doi: 10.1161/ATVBAHA.121.316929

18. Tuersun T, Luo Q, Zhang Z, Wang G, Zhang D, Wang M, et al. Abdominal aortic calcification is more severe in unilateral primary aldosteronism patients and is associated with elevated aldosterone and parathyroid hormone levels. Hypertens Res. (2020) 43:1413-20. doi: 10.1038/s41440-020-0529-7

19. Liu P, Zhang S, Gao J, Lin Y, Shi G, He W, et al. Downregulated serum 14, 15-epoxyeicosatrienoic acid is associated with abdominal aortic calcification in patients with primary aldosteronism. Hypertension. (2018) 71:592-8. doi: 10.1161/HYPERTENSIONAHA.117.10644

20. Bäck M, Michel J-B. From organic and inorganic phosphates to valvular and vascular calcifications. Cardiovasc Res. (2021) 117:2016-29. doi: 10.1093/cvr/cvab038

21. Pasch A, Jahnen-Dechent W, Smith ER. Phosphate, calcification in blood, and mineral stress: the physiologic blood mineral buffering system and its association with cardiovascular risk. Int J Nephrol. (2018) 2018:9182078. doi: 10.1155/2018/9182078

22. Pasch A, Farese S, Gräber S, Wald J, Richtering W, Floege J, et al. Nanoparticlebased test measures overall propensity for calcification in serum. J Am Soc Nephrol. (2012) 23:1744-52. doi: 10.1681/ASN.2012030240

23. Eelderink C, Te Velde-Keyzer CA, Frenay ARS, Vermeulen EA, Bachtler M, Aghagolzadeh P, et al. Serum calcification propensity and the risk of cardiovascular and all-cause mortality in the general population: the PREVEND study. Arterioscler Thromb Vasc Biol. (2020) 40:194251. doi: 10.1161/ATVBAHA.120.314187

24. Smith ER, Ford ML, Tomlinson LA, Bodenham E, McMahon LP, Farese S, et al. Serum calcification propensity predicts all-cause mortality in predialysis CKD. J Am Soc Nephrol. (2014) 25:339-48. doi: 10.1681/ASN.2013060635

25. Pasch A, Block GA, Bachtler M, Smith ER, Jahnen-Dechent W, Arampatzis $\mathrm{S}$, et al. Blood calcification propensity, cardiovascular events, and survival in 
patients receiving hemodialysis in the EVOLVE Trial. Clin J Am Soc Nephrol. (2017) 12:315-22. doi: 10.2215/CJN.04720416

26. Dahle DO, Åsberg A, Hartmann A, Holdaas H, Bachtler M, Jenssen TG, et al. Serum calcification propensity is a strong and independent determinant of cardiac and all-cause mortality in kidney transplant recipients. Am J Transplant. (2016) 16:204-12. doi: 10.1111/ajt.13443

27. Funder JW, Carey RM, Mantero F, Murad MH, Reincke M, Shibata H, et al. The management of primary aldosteronism: case detection, diagnosis, and treatment: an endocrine society clinical practice guideline. J Clin Endocrinol Metab. (2016) 101:1889-916. doi: 10.1210/jc.2015-4061

28. Williams B, Mancia G, Spiering W, Rosei EA, Azizi M, Burnier M, et al. 2018 ESC/ESH Guidelines for themanagement of arterial hypertension. Eur Heart J. (2018) 39:3021-104. doi: 10.1093/eurheartj/ehy439

29. Grundy SM, Stone NJ, Bailey AL, Beam C, Birtcher KK, Blumenthal RS, et al. 2018 AHA/ACC/AACVPR/AAPA/ABC/ACPM/ADA/AGS/APhA/ASPC/NLA/PCNa guideline on the management of blood cholesterol: a report of the American College of Cardiology/American Heart Association Task Force on Clinical Practice Guidelines. Circulation. (2019) 139:E1082-143. doi: 10.1161/CIR.0000000000000624

30. O'Connor SD, Graffy PM, Zea R, Pickhardt PJ. Does nonenhanced CT-based quantification of abdominal aortic calcification outperform the framingham risk score in predicting cardiovascular events in asymptomatic adults? Radiology. (2019) 290:108-15. doi: 10.1148/radiol.2018180562

31. Ichii M, Ishimura E, Shima H, Ohno Y, Ochi A, Nakatani S, et al. Quantitative analysis of abdominal aortic calcification in CKD patients without dialysis therapy by use of the agatston score. Kidney Blood Press Res. (2014) 38:196204. doi: $10.1159 / 000355768$

32. Mencke R, Van Der Vaart A, Pasch A, Harms G, Waanders F, Bilo $\mathrm{HJG}$, et al. Serum calcification propensity is associated with HbAlc in type 2 diabetes mellitus. BMJ Open Diabetes Res Care. (2021) 9:e002016. doi: 10.1136/bmjdrc-2020-002016

33. Pruijm M, Lu Y, Megdiche F, Piskunowicz M, Milani B, Stuber M, et al. Serum calcification propensity is associated with renal tissue oxygenation and resistive index in patients with arterial hypertension or chronic kidney disease. J Hypertens. (2017) 35:2044-52. doi: 10.1097/HJH.0000000000001406

34. Bundy JD, Cai X, Scialla JJ, Dobre MA, Chen J, Hsu C, et al. Serum calcification propensity and coronary artery calcification among patients with CKD: The CRIC (chronic renal insufficiency cohort) study. Am J Kidney Dis. (2019) 73:806-14. doi: 10.1053/j.ajkd.2019.01.024

35. Voelkl J, Alesutan I, Leibrock CB, Quintanilla-Martinez L, Kuhn V, Feger M, et al. Spironolactone ameliorates PIT1-dependent vascular osteoinduction in klotho-hypomorphic mice. J Clin Invest. (2013) 123:81222. doi: 10.1172/JCI64093

36. Zhang S, Wang N, Chen L, Zhang P, Shen L, Huang S, et al. Serum aldosterone is associated with cerebral artery atherosclerosis and calcification. J Stroke Cerebrovasc Dis. (2019) 28:523-30. doi: 10.1016/j.jstrokecerebrovasdis.2018.09.053

37. Inoue $\mathrm{K}$, Goldwater $\mathrm{D}$, Allison $\mathrm{M}$, Seeman $\mathrm{T}$, Kestenbaum $\mathrm{BR}$, Watson KE. Serum aldosterone concentration, blood pressure, and coronary artery calcium. Hypertension. (2020) 76:11320. doi: 10.1161/HYPERTENSIONAHA. 120.15006

38. Nitta $K$, Akiba $T$, Nihei $H$. Aldosterone blockade and vascular calcification in hemodialysis patients. Am J Med. (2003) 115:250a. doi: 10.1016/S0002-9343(03)00293-6

39. Jaffe IZ, Tintut Y, Newfell BG, Demer LL, Mendelsohn ME. Mineralocorticoid receptor activation promotes vascular cell calcification. Arterioscler Thromb Vasc Biol. (2007) 27:799-805. doi: 10.1161/01.ATV.0000258414.59393.89

40. Gao J, Zhang K, Chen J, Wang MH, Wang J, Liu P, et al. Roles of aldosterone in vascular calcification: an update. Eur J Pharmacol. (2016) 786:186-93. doi: 10.1016/j.ejphar.2016.05.030

41. Hammer F, Buehling SS, Masyout J, Malzahn U, Hauser T, Auer T, et al. Protective effects of spironolactone on vascular calcification in chronic kidney disease. Biochem Biophys Res Commun. (2021) 582:2834. doi: 10.1016/j.bbrc.2021.10.023

42. Buonafine M, Bonnard B, Jaisser F. Mineralocorticoid receptor and cardiovascular disease. Am J Hypertension. (2018) 31:116574. doi: $10.1093 /$ ajh/hpy120
43. Barrera-Chimal J, Lima-Posada I, Bakris GL, Jaisser F. Mineralocorticoid receptor antagonists in diabetic kidney disease - mechanistic and therapeutic effects. Nat Rev Nephrol. (2021) 18:56-70. doi: 10.1038/s41581-021-00490-8

44. Lorenz G, Steubl D, Kemmner S, Pasch A, Koch-Sembdner W, Pham $\mathrm{D}$, et al. Worsening calcification propensity precedes all-cause and cardiovascular mortality in haemodialyzed patients. Sci Rep. (2017) 7:13368. doi: 10.1038/s41598-017-12859-6

45. Resnick LM, Muller FB, Laragh JH. Calcium-regulating hormones in essential hypertension: relation to plasma renin activity and sodium metabolism. Ann Intern Med. (1986) 105:649-54. doi: 10.7326/0003-4819-105-5-649

46. Tomaschitz A, Ritz E, Pieske B, Rus-Machan J, Kienreich K, Verheyen $\mathrm{N}$, et al. Aldosterone and parathyroid hormone interactions as mediators of metabolic and cardiovascular disease. Metabolism. (2014) 63:2031. doi: 10.1016/j.metabol.2013.08.016

47. Zheng MH Li FXZ, Xu F, Lin X, Wang Y, Xu QS, et al. The interplay between the renin-angiotensin-aldosterone system and parathyroid hormone. Front Endocrinol (Lausanne). (2020) 11:539. doi: 10.3389/fendo.2020.0 0539

48. Leclerc M, Brunette MG, Couchourel D. Aldosterone enhances renal calcium reabsorption by two types of channels. Kidney Int. (2004) 66:242-50. doi: $10.1111 / j .1523-1755.2004 .00$ 725. $\mathrm{x}$

49. Alesutan I, Tuffaha R, Auer T, Feger M, Pieske B, Lang F, et al. Inhibition of osteo/chondrogenic transformation of vascular smooth muscle cells by $\mathrm{MgCl} 2$ via calcium-sensing receptor. $J$ Hypertens. (2017) 35:523-32. doi: 10.1097/HJH.000000000000 1202

50. Montezano AC, Zimmerman D, Yusuf H, Burger D, Chignalia AZ, Wadhera $\mathrm{V}$, et al. Vascular smooth muscle cell differentiation to an osteogenic phenotype involves TRPM7 modulation by magnesium. Hypertension. (2010) 56:453-62. doi: 10.1161/HYPERTENSIONAHA.110.15 2058

51. Kieboom BCT, Niemeijer MN, Leening MJG, van den Berg ME, Franco $\mathrm{OH}$, Deckers JW, et al. Serum magnesium and the risk of death from coronary heart disease and sudden cardiac death. J Am Heart Assoc. (2016) 5:1-11. doi: 10.1161/JAHA.115.00 2707

52. Fang $X$, Wang $K$, Han D, He X, Wei J, Zhao L, et al. Dietary magnesium intake and the risk of cardiovascular disease, type 2 diabetes, and all-cause mortality: a dose-response meta-analysis of prospective cohort studies. BMC Med. (2016) 14:210. doi: 10.1186/s12916-016-0 $742-\mathrm{z}$

53. Guasch-Ferré M, Bulló M, Estruch R, Corella D, MartínezGonzález MA, Ros E, et al. Dietary magnesium intake is inversely associated with mortality in adults at high cardiovascular disease risk. J Nutr. (2014) 144:55-60. doi: 10.3945/jn.113.18 3012

54. ter Braake AD, Vervloet MG, de Baaij JHF, Hoenderop JGJ. Magnesium to prevent kidney disease-associated vascular calcification: crystal clear? Nephrol Dial Transplant. (2020). 2020:gfaa222. doi: 10.1093/ndt/gfa a222

55. Ter Braake AD, Eelderink C, Zeper LW, Pasch A, Bakker SJL, De Borst $\mathrm{MH}$, et al. Calciprotein particle inhibition explains magnesium-mediated protection against vascular calcification. Nephrol Dial Transplant. (2020) 35:765-73. doi: 10.1093/ndt/gf z190

56. Bressendorff I, Hansen D, Schou M, Pasch A, Brandi L. The effect of increasing dialysate magnesium on serum calcification propensity in subjects with end stage kidney disease: a randomized, controlled clinical trial. Clin J Am Soc Nephrol. (2018) 13:1373-80. doi: 10.2215/CJN.1392 1217

57. Weber KT. Aldosteronism revisited: perspectives on less well-recognized actions of aldosterone. J Lab Clin Med. (2003) 142:71-82. doi: 10.1016/S0022-2143(03)00 $062-3$

58. Pasch A. Novel assessments of systemic calcification propensity. Curr Opin Nephrol Hypertens. (2016) 25:278-84. doi: 10.1097/MNH.000000000000 0237 
Conflict of Interest: AP is an employee and stockholder of Calciscon AG, which commercializes the T50 test.

The remaining authors declare that the research was conducted in the absence of any commercial or financial relationships that could be construed as a potential conflict of interest.

Publisher's Note: All claims expressed in this article are solely those of the authors and do not necessarily represent those of their affiliated organizations, or those of the publisher, the editors and the reviewers. Any product that may be evaluated in this article, or claim that may be made by its manufacturer, is not guaranteed or endorsed by the publisher.

Copyright (c) 2022 Kantauskaite, Bolten, Boschheidgen, Schmidt, Kolb, Eckardt, Pasch, Schimmöller, Rump, Voelkl and Stegbauer. This is an open-access article distributed under the terms of the Creative Commons Attribution License (CC BY). The use, distribution or reproduction in other forums is permitted, provided the original author(s) and the copyright owner(s) are credited and that the original publication in this journal is cited, in accordance with accepted academic practice. No use, distribution or reproduction is permitted which does not comply with these terms. 